\title{
Cambio climático y apocalipsis: una mirada desde la geografía cultural a partir de un texto del geógrafo Erik Swyngedouw
}

\author{
Swyngedouw, E. (2021). El apocalipsis es decepcionante: el punto muerto despolitizado del \\ consenso sobre el cambio climático. Revista Punto Sur, 5, 6-23.
}

Andrés Núñez

Instituto de Geografía, Pontificia Universidad Católica de Chile.

En los días que se escribe este comentario al texto del geógrafo inglés Erik Swyngedouw, Chile vive un invierno especialmente seco, pocas lluvias y una mezcla de días de calor y frío. Por lo mismo, por una parte, los periódicos se llenan de artículos y expresiones de horror ante un escenario tan complejo. Y en efecto lo es, porque aquello implicará falta de agua para riego y eventualmente, como muchos ya anuncian, para el consumo humano. Es decir, tal vez haya racionamiento. Por otra parte, subrayan que el clima ha cambiado, que esto ya ha sido anunciado por los científicos y que si no reaccionamos a tiempo la "naturaleza" nos enviará una suerte de castigo ante tanta acción inconsciente por parte de lo que se conoce como humanidad.

Todo este panorama me resulta intrigante y no puedo evitar preguntarme por el aporte a la discusión que puede hacerse desde la mirada de un geógrafo cultural. Surge entonces la pregunta: ¿̇cómo leer los discursos sobre la crisis climática sin caer en una lógica apocalíptica o en esencialismos modernos sobre la "madre naturaleza" y sus castigos? Estimo que, en el contexto de esta pregunta, el texto que nos entrega Swyngedouw, titulado El apocalipsis es decepcionante: el punto muerto despolitizado del consenso sobre el cambio climático resulta un vital y notable aporte. Uno puede discrepar de algunos asuntos, a los que me referiré más adelante, pero poner a la vista una perceptiva menos masiva es sin duda muy enriquecedor, especialmente cuando sus conectores son otros. Girar del punto de vista dominante, como diría Nietzsche o Foucault, será siempre abrir una ventana allí donde se observa una pared. En otras palabras, será un trabajo que deshegemoniza la mirada. Eso es, en mi opinión, lo que puede aportar un geógrafo cultural, donde me parece posible incluir el trabajo de Swyngedouw.

¿Qué es lo central de este escrito? Estimo que hay muchos elementos tan importantes como interesantes, pero desde mi perspectiva, lo central de su aporte sería "prenderle la luz" a una puesta en escena donde la crisis climática es subsumida en pura representación, en pura discursividad abstracta. Ese encender la luz vendría a ser la mirada crítica del elemento que se analiza y que, en consecuencia, desnuda el drama apocalíptico con que se ha ido escenificando el problema climático, olvidando o invisibilizando conexiones que podrían entenderse como la base del problema. El texto de Swyngedouw no niega el cambio y crisis climática (¿quién lo podría negar?), pero lo saca del anclaje cultural donde busca instalarse, es decir, como algo fijo, estático, técnico, sin relaciones, 
sin agencias vinculantes que lo produzcan; paradójicamente un cambio climático "sin cambio”. Cómo él dice: “(...) muchas de las intervenciones climáticas tienden a ser dispositivos tecno-gerenciales poco efectivos, aunque triunfalmente declarados como capaces de romper con la tendencia evolutiva y estabilizar el clima, de modo que las cosas puedan continuar como de costumbre" (Swyngedouw, 2021:pp). En otras palabras, que todo cambie para que nada cambie. Pareciera ser que la crisis climática, como él mismo expresa, es una cosa dada, "natural", sin trayectorias de producción ni ensamblajes de las relaciones de poder que la exponen o fabrican. Tal panorama hace que la crisis climática se torne un asunto netamente técnico-científico, se despolitice y pierda la indispensable mirada hacia el sistema socio-ecológico en el que está inserta.

Desde este contexto, me parece necesario resaltar algunos de los elementos que el texto expresa y que pueden servir para abrir nuevas preguntas sobre este tema tan complejo. Expondré los que me resultan más relevantes para luego ver un par de asuntos que serán interrogantes al planteo de Swyngedouw, pero que, por razones obvias, solo serán expuestas de modo muy general.

En primer lugar, el trabajo expresa que gran parte de la discusión de la crisis ambiental y climática se ha dado en torno a un "desplazamiento fetichista de los procesos socioecológicos”, donde el centro del problema estaría en el $\mathrm{CO} 2$ y en las medidas que todos los "humanos" deberíamos aplicar para reducir sus niveles de emisión. Swyngedouw llama a ese fetiche "la cosa" desde donde "se establece la acción y la simbolización". Desde su punto de vista, esta lectura socio-ecológica invisibiliza relaciones de poder y los engranajes de producción de lo visible, el calentamiento global y el efecto invernadero:

No serían las relaciones de poder, ya sean de clase u otras, y la expansiva universalidad del capitalismo lo que constituye, las emisiones de gases que producen el efecto invernadero, sino que es esta cosa gaseosa -como configuración en sí misma- alrededor de la cual circula la simbolización y, por lo tanto, las políticas, las intervenciones, los discursos, las instituciones, las acciones y las tecnologías (Swyngedouw, 2021: 9).

Este es un aspecto muy interesante porque en efecto, por una parte, retoma la necesidad de observar el asunto desde la materialidad del problema y no desde la clásica mirada binaria (tan abstracta como idealista, como diría Deleuze (2019a)) de separar lo humano de la naturaleza, donde sería la naturaleza quien nos estaría haciendo una mala jugada. Por lo mismo, le interesa poner el foco no en la cosa fetiche -el $\mathrm{CO}_{2}-$, sino en las complejas y múltiples relaciones a través de las cuales se desenvuelven los cambios ambientales, no ajenas al poder ni al tipo de sistema socio-ecológico que predomina hace ya varios siglos.

Un segundo aspecto que, vinculado al anterior, también resulta muy importante de rescatar o de reforzar en este comentario es algo que Bruno Latour ha venido exponiendo hace ya algún tiempo. Nos referimos al estrecho vínculo entre saber y poder (esa combinación que fue el centro del trabajo de Foucault) y desde este contexto, como expresa el propio Latour, a una mayor sumisión del saber científico al fetiche o "cosa" que en la búsqueda de razones que producen el problema; problema que siendo técnico es a su vez tan cultural como político. Los científicos, dice Latour, en su afán de alcanzar "neutralidad" buscan leyes indefectibles de naturaleza indiferente a una función que 
no es separable del saber y del poder (Latour, 2017). Y no es que la ciencia no aporte, por el contrario, solo que las relaciones -los ensamblajes que realiza- se quedan en una cápsula y no salen a la calle, por así decirlo, a lo social, a desmontar al poder-saber. En la misma línea, Swyngedouw plantea que "las discusiones ambientales le otorgan a la comunidad científica y a las élites políticas un rol de portador de verdad”. Así, las universidades y la producción de conocimiento asociada implican la búsqueda de una arquitectura política supuestamente neutral, idealmente alejada de la interpretación, pero desde donde nuevamente se cosifica el problema. Tal producción queda, en cierto modo, relegada a laboratorios de medición o grupos herméticos de investigación que buscan instalar modelos de predicción donde el lenguaje apocalíptico inunda la hoja de sus informes (una "retórica alarmista" como él define). Vale la pena preguntarse, cuanto y cómo aportan realmente las universidades y lo que reconocemos como "ciencia" a una discusión ambiental efectiva:

(...) se reduce el síndrome patológico a esa cosa objetivada y fetichizada (el $\mathrm{CO}_{2}$ y otros gases de efecto invernadero) que se presenta como el objeto-causa de preocupación, el cual pude controlarse mediante ajustes sociotécnicos, de gestión y de consumo; lo que oscurece aún más las relaciones socio-ecológicas y políticas que sostienen el cambio climático (Swyngedouw, 2021: 10).

Desde esta descripción, uno se pregunta cuántos de los grupos ambientalistas y los expertos ya aludidos vienen a agudizar el problema en lugar de solucionarlo, toda vez que instalan y refuerzan la discusión desde "lo técnico" (por lo tanto, desde un umbral abstracto) y no desde el indispensable desmontaje de los elementos que lo componen, donde el capitalismo y el modo de vida asociado a su sistema cumplen una función relevante en la producción de la crisis. Como diría Deleuze (2006), más allá de que en apariencia se vean como parte de un mismo cuadro, no todos los engranajes de un dispositivo (aquello que cruza las relaciones de poder con las relaciones del saber) son iguales, ya que hay máquinas sociales o potencias que influyen de modo más protagónico en la colonización cultural y en la fijación piramidal de un territorio, en este caso, el capitalista.

En tercer lugar, y último, resalto un elemento de otros posibles de leer en el artículo. Me refiero a lo que Swyngedouw llama "la inmuno-biopolítica de la adaptación" o la aislación hermética "del objeto de gobierno (la población)". Hay en ello un disciplinamiento muy interesante que en el fondo configura una, para decirlo en términos foucaulteanos, gubernamentalidad (o ambientabilidad en términos de Arun, 2005) asociada a prácticas donde el ciudadano "aportará con su granito de arena" a la estabilidad del clima (ialgo tan absurdo como imposible!) o a disminuir la brecha del calentamiento global. Esto, como expone el geógrafo belga, evita el disenso y vuelve a los individuos parte de una comunidad de escala global que se suma a la "cruzada" de salvar al planeta:

De hecho, la búsqueda de una biopolítica inmunológica es uno de los pocos terrenos que le quedan al poder estatal en un mundo en donde la privatizaciónmercantilización de todo, combinada con un vaciamiento de su soberanía territorial -precisamente debido a los procesos de globalización-, ha fomentado la reorientación de las funciones estatales hacia la gestión de la población y su felicidad. La inmuno-biopolítica es, por lo tanto, uno de los dispositivos estructurantes de vital importancia en el proceso de hegemonización de la pospolitización tecno-gerencial (Ernstson y Swyngedouw, 2018 en Swyngedouw, 2021: 15-16). 
Esta producción de un sujeto ambiental calza muy bien con llamados como el que hizo una ministra chilena hace no mucho tiempo atrás al pedir que, para aportar a reducir el problema de la crisis ambiental, los y las ciudadanas debíamos ducharnos en solo tres minutos como máximo. Desde esta lógica de control de la población como garante del problema climático, se invisibilizan las escalas y relaciones de otros niveles en tanto cada uno de nosotros sería responsable de la crisis climática actual. De allí que la imagen apocalíptica sea útil al control de los cuerpos sociales. A esto Swyngedouw lo llama "la gestión del miedo" citando a Alan Badiou:

En otras palabras, la presentación del cambio climático como una causa humanitaria a nivel global produce un imaginario completamente despolitizado en donde no se trata de elegir una trayectoria en lugar de otra, o de identificar enemigos dentro de un proceso político. Se trata de un imaginario que no se articula con programas políticos específicos o con proyectos o transformaciones socio-ecológicas (Swyngedouw, 2018 en Swyngedouw, 2021: 17).

En esto hay otro punto interesante: se instala a la crisis ambiental en el futuro, pero, como expresa Swyngedouw, ella ya estaría aquí en cuanto es posible observarla en las desigualdades socio-ecológicas como en los conflictos por el agua, las luchas por el alimento, los refugiados ambientales o la apropiación capitalista de amplias zonas "verdes" -tal como hemos venido exponiendo con el geógrafo chileno Enrique Aliste hace ya algunos años, en lo que hemos llamado el eco-extractivismo (Aliste et al., 2018; Núñez et al., 2019a, 2019b, 2020)-.

Este aspecto es muy relevante para mi análisis porque, en este caso, las prácticas y las experiencias climáticas son transitadas, antes de todo, por el cuerpo. Un cuerpo normalizado como sustentable, disciplinado para ser ambientalista y "verde", sería la expresión a partir de la cual el sujeto se desenvuelve sobre el territorio globalizado. ¿Cómo se crea este cuerpo sustentable? Por una parte, desde el discurso del colonizador (tanto capitalista como estatal) que lo empuja a sentirse "otro", un ser excepcional que lucha por algo superior (la "vida" o la "naturaleza", por ejemplo), por una escala -y una moral- de alcance global. Mas, por otra parte, aquella corporalidad sustentable es fabricada por un lento caminar de conexiones y acoplamientos diversos: el reciclaje, energía solar en las casas, huertas ecológicas, bolsas de papel, etc. Son estas materialidades las que van fijando el devenir-cuerpo-sustentable y le dan sentido al designio moral del colonizador global, en tanto co-fabrican el proyecto sostenible para el mundo y la vida. Entonces, la producción de un sujeto sustentable sería, siguiendo a Deleuze (2006) y a Sundberg (2017), el relato de esos pliegues materiales que van configurando al cuerpo: "Lo íntimo como categoría analítica o como sitio corporifica las relaciones sociales, y los objetos, las actitudes y las prácticas disciplinarias que sirven como fuentes de identificación o de formación identitaria" (Sundberg, 2017:10). Los cuerpos, de hecho, asimilan los discursos y los hacen carne, práctica y habitar, ya que solo de este modo el proceso disciplinario de ser sustentable, transformado en actitud moral, se dispersa territorialmente. Todas estas actitudes son, en el fondo, experiencias asociadas a posiciones sociales y geopolíticas de los sujetos que las transitan (Mora et al., 2009).

Para terminar, dos aspectos que solo enunciaré a nivel de inquietudes porque, sin duda, son problemas amplios que no dan cabida para un texto como este. El primero es sobre su crítica a la posverdad como él llama a todo lo que en principio se alejaría 
de "lo Real". Esta es una insistente interpretación marxista a lo que se conoce como posmodernidad. Sin embargo, me parece que el asunto es más complejo y probablemente el artículo supera los intereses de un análisis como este. $Y$ lo expreso porque considero que, junto al análisis marxista profundamente estructuralista, también es posible sumar las miradas postestructuralistas al problema del clima, sin perder por ello la mirada crítica. De hecho, en parte el mismo Swyngedouw lo hace al tratar el tema de la biopolítica. Estoy de acuerdo, por ejemplo, como ha planteado insistentemente Žižek, que la posverdad es un tipo de discurso que en el fondo se vuelve amante de la diferencia, olvidando (para decirlo en términos deleuzeanos) una repetición devenida en representación que significa observar un mundo global de "libertades capitalistas", pero cargado de explotación e injusticias territoriales. Sin embargo, desde otro prisma, todo el trabajo de Foucault y de Deleuze (2019b)/ Guattari (2013) ha permitido instalar miradas tan descolonizadoras como las formuladas desde el ámbito marxista. De hecho, desde mi punto de vista, el análisis de Deleuze (2006)/ Guattari (2013) es profundamente revolucionario en cuanto también es un retorno a la materialidad, pero fundamentalmente al interés por poner fin a la mirada binaria, con lo que se avanzaría sustancialmente en el fin del proyecto de la modernidad. A su vez, es muy interesante constatar, como lo hacen ellos, que las relaciones de fuerza son producciones por relación y no por oposición o negación, con lo que se alejan de la dialéctica estructuralista y nos acercan a la existencia de una fuerza activa y de la afirmación de su diferencia, diferencia que surge por jerarquía. Esta fue, por ejemplo, la base de la producción de un territorio latinoamericano subdesarrollado, salvaje e incivilizado, a través de la cual la voluntad de poder europea narró su diferencia.

Un segundo aspecto es que Swyngedouw no menciona la relación entre el rol del Norte (Inglaterra, por ejemplo) y la aceleración del calentamiento global o la crisis ambiental. Si pusiésemos en una balanza los aportes del Sur al calentamiento global probablemente serían ridículos con los que se generan desde el Norte Global. Hay allí un tema de fondo. Como es sabido, los estudios culturales y los poscoloniales han buscado cambiar esta mirada, pero también lo hacen desde la comodidad de un nivel de producción y consumo que solo agudiza la crisis climática. El problema del Norte, aún con todo el impulso por las cumbres ambientales, es que en el fondo nos piden a los del Sur que hagamos mayores sacrificios para nuevos equilibrios ambientales globales, lo que se traduce en grandes sumas de dinero para ciclovías, educación ambiental o basureros de reciclaje. Pero, en el fondo, eso también sería "hacer todo para que nada cambie", como él mismo expone a propósito de otros roles.

En definitiva, un texto tan fascinante como necesario y oportuno, indispensable desde mi punto de vista. Estimo que la geografía en general se ve muy enriquecida con esta mirada crítica y cultural, que coloca el énfasis en la necesidad de incorporar nuevas conexiones en el análisis, sacando en cierto modo al problema ambiental de la despolitización en que ha sido instalado. Solo un dato confirma mucho de lo expuesto por Swyngedouw: en el año 2019, en lo que podría reconocerse como una información de total actualidad, la empresa estatal de petróleos de Arabia Saudita, Aramco, obtuvo el mayor debut bursátil de la historia, después de que aumentara un $10 \%$ el valor de sus acciones sobre el precio inicial, pocas horas después la apertura de los mercados en la bolsa de valores de Riad. Desde este punto de vista, Aramco es señalada como la empresa más rentable del planeta (iaunque el petróleo sea el responsable principal de la crisis ambiental!). Si esto es así, uno se pregunta, como lo hace el propio geógrafo belga, 
Cambio climático y apocalipsis: una mirada desde...

ANDRÉS NÚÑEZ

¿por qué este tipo de asociaciones entre crisis ambiental y el sistema socio-ecológico dominante no se instala en el centro de la discusión? Tal vez, como lo expone el geógrafo norteamericano Jason Moore (2020), no estemos en la era del Antropoceno sino la del Capitaloceno. Estimo que por lo menos es un asunto para reflexionar.

Este trabajo se realizó con el apoyo del proyecto Fondecyt $N^{\circ} 1210944$. 


\section{Q Bibliografía}

》Aliste, E., Folchi, M. y Núñez, A. (2018). Discourses of nature in new perceptions of the natural landscape in Southern Chile. Frontiers in Psychology, 9, 1177.

» Arun, A. (2005). Environmentality:Technologies of Government and the Making of Subjects. Durham: Duke University Press.

"Deleuze, G. (2019a). Nietzsche. Buenos Aires: Cactus.

》Deleuze, G. (2019b). La subjetivación, curso sobre Foucault. Buenos Aires: Cactus.

"Deleuze, G. (2006). Diferencia y repetición. Buenos Aires: Amorrortu.

" Guattari, F. (2013). Líneas de fuga: por otro mundo de posibles. Buenos Aires: Cactus.

»Latour, B. (2017). Cara a cara con el planeta. Una nueva mirada sobre el cambio climático alejada de las posiciones apocalípticas. Buenos Aires: Siglo Veintiuno.

» Moore, J. (2020). El capitalismo en la trama de la vida. Ecología y acumulación de capital. Madrid: Traficantes de sueños.

» Mora, B. y Montenegro, M. (2009). Fronteras internas, cuerpos marcados y experiencia de fuera de lugar. Las migraciones internacionales bajo las actuales lógicas de explotación y exclusión del capitalismo global. Athenea Digital,15, 1-19.

» Núñez, A., Benwell, M. y Aliste, E. (2020). Interrogating green discourses in Patagonia-Aysén (Chile): green grabbing and eco-extractivism as a new strategy of capitalism? Geographical Review, 1-19.

»Núñez, A., Aliste, E., Bello, A. y Astaburuaga, J. (2019a). Eco-extractivismo y los discursos de la naturaleza en Patagonia-Aysén: nuevos imaginarios geográficos y renovados procesos de control territorial. Revista Austral de Ciencias Sociales, 35, 133-153.

》Núñez, A., Miranda, F., Aliste Almuna, E. y Urrutia, S. (2019b). Conservacionismo y desarrollo sustentable en la geografía del capitalismo: negocio ambiental y nuevas formas de colonialidad en Patagonia-Aysén. En A. Núñez, E. Aliste y R. Molina (Comps.), (Las) Otras Geografías en Chile. Perspectivas sociales y enfoques críticos (pp. 23-46). Santiago de Chile: LOM Ediciones.

»Sundberg, J. (2017). Fronteras íntimas y geopolítica cotidiana en la zona fronteriza entre Estados Unidos-México. Revista de Geografía Norte Grande, 66, 9-32.

\section{Andrés Núñez / andresnunezg@gmail.com}

Doctor en Historia por la Universidad Católica de Chile. Llevó a cabo su proyecto posdoctoral en el Instituto de Geografía de la misma casa de estudios. Es profesor asociado-jornada completa del citado instituto, donde, junto a la investigación, imparte docencia. Su área de investigación se enmarca en la línea de la Geografía Social, Geografía Cultural y Geografía Histórica. En la actualidad trabaja en torno a las Ontologías Relacionales y la obra de Gilles Deleuze. 